\title{
Cancer and Thrombosis: Managing the Risks and Approaches to Thromboprophylaxis
}

\author{
Erhard Hiller \\ Faculty of Medicine, Ludwig-Maximilians-Universität München, Germany
}

Key Words

Anticoagulants - Low-molecular-weight heparin · Warfarin - Coumarin derivatives - Venous thrombosis

\section{Summary}

Patients with cancer are at increased risk of venous thromboembolism (VTE) compared with patients without cancer. This results from both the prothrombotic effects of the cancer itself and iatrogenic factors, such as chemotherapy, radiotherapy, indwelling central venous devices and surgery, that further increase the risk of VTE. Although cancer-associated thrombosis remains an important cause of morbidity and mortality, it is often underdiagnosed and undertreated. However, evidence is accumulating to support the use of low-molecular-weight heparins (LMWHs) in the secondary prevention of VTE in patients with cancer. Not only have LMWHs been shown to be at least as effective as coumarin derivatives in this setting, but they have a lower incidence of complications, including bleeding, and are not associated with the practical problems of warfarin therapy. Furthermore, a growing number of studies indicate that LMWHs may improve survival among patients with cancer due to a possible antitumor effect. Current evidence suggests that LMWHs should increasingly be considered for the longterm management of VTE in patients with cancer.

\author{
Schlüsselwörter \\ Antikoagulanzien - Niedermolekulares Heparin . \\ Warfarin · Cumarinderivate · Venöse Thrombose
}

\section{Zusammenfassung}

Krebspatienten unterliegen im Vergleich zu Patienten ohne Krebs einem erhöhten Risiko, venöse Thromboembolien (VTE) zu erleiden. Gründe dafür sind die prothrombotischen Effekte der Krebserkrankung selbst, aber zusätzlich erhöhen auch iatrogene Faktoren wie Chemotherapie, Strahlentherapie, zentrale Venenkatheter und operative Eingriffe das VTE-Risiko. Obwohl die krebsassoziierte Thrombose häufig ursächlich für Morbidität und Mortalität ist, wird sie oft zu wenig diagnostiziert und nicht adäquat behandelt. Es gibt zunehmende Hinweise dafür, dass niedermolekulare Heparine (NMHs) in der sekundären Thromboseprophylaxe von Krebspatienten von Vorteil sind. Sie sind nicht nur den Cumarinderivaten in dieser Indikation mindestens ebenbürtig, sondern führen auch zu weniger Komplikationen, insbesondere, was Blutungen anbelangt, und sind auch nicht mit den praktischen Problemen der Warfarintherapie belastet. Darüber hinaus gibt es basierend auf Studien zunehmend Hinweise, das NMHs durch mögliche Antitumor-Effekte das Leben von Krebspatienten verlängern könnten. Aufgrund der gegenwärtigen Datenlage sprechen einige Fakten dafür, NMHs zunehmend in der Langzeittherapie von Krebspatienten mit VTE einzusetzen.

\begin{tabular}{ll}
\hline KARGER & @ 2006 S. Karger GmbH, Freiburg \\
$\begin{array}{l}\text { Fax +49 76145207 14 } \\
\begin{array}{l}\text { E-mail Information@Karger.de } \\
\text { www.karger.com }\end{array}\end{array}$ & $\begin{array}{l}\text { Accessible online at: } \\
\text { www.karger.com/onk }\end{array}$ \\
&
\end{tabular}

Professor Dr. med. Erhard Hiller

Medizinische Fakultät, Ludwig-Maximilians-Universität München

Hämato-onkologische Gemeinschaftspraxis

Winthirstrasse 7, 80639 München, Germany

Tel. +49 89 75-54298, Fax - 979799

E-mail Erhard.Hiller@gmx.de 
Frequency of Venous Thromboembolism in Cancer Patients

Venous thromboembolic disease (VTE) is a common and often underdiagnosed condition in cancer patients. It may be a presenting feature of occult malignancy, a life-threatening complication of early or advanced cancer, or a sequela of cancer therapy. Most clinical studies designed to determine the true incidence of VTE in cancer patients have been neither prospective nor have they included untreated patients. In the 1980s, the incidence of VTE in malignant disease was estimated to be approximately $15 \%$, ranging from 7 to $30 \%$ depending on the tumor site [1]. However, more recently, incidence rates of $8 \%$ have been reported which may reflect the more widespread use of thromboprophylaxis in modern practice [2]. Cancer patients undergoing surgery have at least twice the risk of postoperative deep venous thrombosis (DVT) and more than three times the risk of fatal pulmonary embolism (PE) than noncancer patients undergoing similar procedures [3]. Only a few clinical studies have estimated the prevalence of asymptomatic DVT in cancer patients. One study screened 298 hospice patients, and DVT was detected in $52 \%$ of the patients, mainly those with poor mobility [4]. The clinical importance of asymptomatic VTE is that it can evolve into symptomatic DVT and even life-threatening PE. Furthermore, VTE is the second most common cause of death in patients hospitalized for solid tumors. This may also explain the fact that VTE detection rates at autopsy may be as high as 50\% [5]. Pathogenic mechanisms accounting for the development of VTE in cancer patients include hypercoagulability due to tumor cell activation of clotting, vessel wall injury, and stasis $[1,6,7]$. Non-tumor-derived factors leading to an additional risk of VTE in cancer patients include advanced age, immobility, venous stasis, previous VTE and hereditary thrombophilia [7]. In addition, several iatrogenic factors can also increase the risk of thrombosis, including surgical procedures, chemotherapy, radiotherapy and indwelling central venous devices [8].

\section{Thromboprophylaxis in Cancer Patients}

Patients with cancer who undergo surgery have a much higher risk of postoperative VTE than non-cancer patients [8]. A series of trials has shown that low-dose unfractionated heparin (UFH) and low-molecular-weight heparins (LMWHs) reduce the frequency of postoperative VTE [9-12]. In many of these studies, cancer patients have been included but not separately analyzed. In one large trial of patients undergoing surgery for intra-abdominal and pelvic malignancies, administration of 5,000 units of dalteparin was shown to be significantly more effective than 2,500 units, without increasing the risk of bleeding [13]. In another study of 631 patients who underwent venographic assessment following elective abdominal or pelvic cancer surgery, enoxaparin, $40 \mathrm{mg}$ once daily, was as ef- fective as UFH, with DVT occurring in 14.7 and $18.2 \%$ of patients, respectively [14]. Thus, current evidence indicates that LMWHs are at least as effective as UFH in reducing postoperative DVT and PE, with additional advantages due to the convenience of once-daily dosing.

The optimal duration of initial postoperative thromboprophylaxis in cancer patients is still under consideration. Bergqvist et al. [15] studied the effect of a prolonged prophylaxis (21 days) with enoxaparin $40 \mathrm{mg}$ or placebo after initial treatment with enoxaparin for 7 days in patients with surgery for abdominal or pelvic cancer. The rate of VTE after 4 weeks was significantly higher in the placebo group (12\%) than in the enoxaparin group (4.8\%). Similar results were shown by Rasmussen et al. [16] in the FAME study in which 590 patients received 5,000 units of dalteparin daily for 1 week and were then randomized to receive a further 3 weeks of dalteparin therapy or no further thromboprophylaxis. Prolonged thromboprophylaxis was associated with a significant reduction in the incidence of VTE from 19.6 to $8.8 \%$.

Non-surgical cancer therapies also increase the risk of VTE. Cancer patients receiving chemotherapy account for $13 \%$ of the overall prevalence of VTE in the population [17]. Further studies are required before recommendations can be made regarding the use of thromboprophylaxis in cancer patients receiving chemotherapy. However, in its 2004 consensus document, the American College of Chest Physicians (ACCP) made a Grade 1A recommendation that thromboprophylaxis appropriate for the current risk state should be routinely administered to hospitalized cancer patients who are bedridden with acute illness [8].

The incidence of catheter-related thrombosis (CRT) in cancer patients with long-term indwelling central venous catheters (CVCs) is highly variable. In a large study of 439 cancer patients undergoing chemotherapy for at least 12 weeks, the administration of dalteparin (5,000 units) did not reduce the frequency of CRT compared with placebo (3.7 vs. $3.4 \%$, respectively; $p=0.88$ ) [18]. Given the low incidence of CRT in cancer patients with CVCs, routine thromboprophylaxis cannot be recommended [8].

\section{Treatment of VTE in Cancer Patients}

The current standard for initial treatment of patients with VTE consists of intravenous UFH or subcutaneous LMWH. Recently, large clinical trials have shown that LMWHs have equivalent efficacy and safety to UFH, and may even be administered in an outpatient setting [19-21]. LMWHs have several pharmacological advantages compared with UFH, which include once- or twice-daily subcutaneous dosing without routine laboratory monitoring [22].

Anticoagulant regimens are generally the same for patients with or without cancer. Although standard therapy for acute VTE is highly effective in many patients, cancer patients have 
Table 1. Cancer patients at low risk of bleeding who should receive fulldose anticoagulant therapy, and patients requiring reduced intensity anticoagulation

\section{Low risk of bleeding - standard anticoagulant therapy}

Patients considered to be cured from cancer, or in complete remission

Hodgkin's and non-Hodgkin's lymphomas

Primary tumor without high bleeding risk (e.g. cancer of breast, lung, pancreas, ovary)

Tumor with only bone metastases

Tumor with only lymph node metastases, or few and small metastases of visceral organs (e.g. lung, liver)

Increased risk of bleeding - reduced intensity of anticoagulation

Tumor or metastases in the brain

Tumors that involve ulceration into the lumen of an organ

(e.g. stomach, bowel, bladder)

Macrohematuria in renal cancer

Currently bleeding tumor

Hereditary or acquired coagulopathy

Thrombocytopenia $(<50,000 / \mu \mathrm{l})$

a 3- to 6-fold increased risk of bleeding and/or recurrent thrombosis during oral anticoagulant therapy, compared with non-cancer patients [23-25]. Furthermore, oral anticoagulant therapy may be problematic in cancer patients because of drug interactions, malnutrition, vomiting and liver dysfunction, all of which may lead to unpredictable levels of anticoagulation. Standard treatment with heparins (UFH or LMWH) and oral anticoagulants should only be administered in the absence of obvious bleeding risks, and reduced doses should be used in patients at risk of bleeding (table 1). Cancer patients with acute DVT and active bleeding cannot generally receive anticoagulant therapy, and there are no standardized antithrombotic regimens in this setting. In some institutions, inferior vena cava filters are inserted in patients with a high risk of PE, but this approach can be problematical as secondary thrombosis of the filter leading to recurrent DVT and fatal PE has been reported [26, 27]. However, in patients with active bleeding, inferior cava filter insertion may be the only option. After hemostasis is achieved, reduced-dose LMWH therapy should be commenced.

\section{Treatment of Recurrent Thrombosis}

Cancer patients have a 2- to 3-fold higher risk of recurrent VTE despite conventional anticoagulant therapy, compared with non-cancer patients $[25,28]$. In the first large-scale study of the prevention of recurrent VTE in patients with cancer, the CLOT trial (Comparison of Low-molecular weight heparin versus Oral anticoagulant Therapy for the prevention of venous thromboembolism in patients with cancer), the efficacy of the LMWH, dalteparin, was compared with coumarin [29]. Patients with acute, symptomatic proximal DVT, PE or both were randomized to receive once-daily dalteparin, 200 units $/ \mathrm{kg}$, for 5-7 days, then a coumarin derivative for 6 months, or dalteparin alone for 1 month, and a lower dose of 150 units/kg for a further 5 months. During the 6-month study period, the risk of VTE was approximately halved in the dalteparin group (9\%) compared with the oral anticoagulant group $(17 \% ; p=0.002)$, with no increase in the risk of major bleeding ( 6 vs. $4 \% ; p=0.27$ ). The long-term administration of tinzaparin has also been evaluated in the management of DVT [30]. Tinzaparin, 175 units/kg once daily, was as effective as a warfarin-based regimen in the prevention of recurrent VTE, with a lower risk of bleeding. The ACCP guidelines on VTE prevention highlight the dalteparin and tinzaparin regimens as approaches that have been shown to be effective [31].

\section{LMWH and Survival in Cancer}

Recent years have seen increasing interest in the possible survival benefits of LMWHs [32-34]. However, these data arise from studies that were not primarily designed to assess cancer mortality, and prognostic variables were not evenly distributed among the treatment groups. The Fragmin Advanced Malignancy Study (FAMOUS) was the first randomized, doubleblind trial to evaluate the effect of long-term LMWH therapy (dalteparin) on survival in cancer patients with no underlying VTE [35]. Patients received either once-daily dalteparin, 5,000 units, or placebo for 1 year. The study did not demonstrate improved 1-year survival rates in patients with advanced malignancy, but post-hoc analysis showed a survival advantage at 17 months in a subgroup of patients with a 'better prognosis' (i.e. those surviving 17 months after randomization). Similarly, post-hoc analysis of the CLOT study demonstrated a survival benefit among patients without metastatic disease at entry into the study who received dalteparin (probability of death, $20 \%$ ) compared with oral anticoagulant (36\%) [36].

In the Malignancy and Low Molecular-Weight Heparin Therapy (MALT) study, a survival benefit was shown among patients with advanced cancer who received a 6-week administration of nadroparin, compared with placebo [37]. Several different tumor types were included in this study, and a significant survival advantage was observed with LMWH, for both the study population as a whole and the subgroup of 'better prognosis' patients. Similar findings were reported in an earlier trial of patients with small-cell lung cancer: those treated with UFH for 5 weeks had a higher 1-year survival rate (40\%) than untreated patients (30\%) [38]. In another trial of patients with small-cell lung cancer, standard combination chemotherapy was administered alone or in combination with dalteparin for 18 weeks. Median overall survival increased from 8.0 months with chemotherapy alone to 13.0 months with combined therapy [39]. Similar survival benefits were observed in patients with both limited and extensive disease who received LMWH. In contrast, 2 recent studies of certoparin administra- 
tion in patients with advanced breast cancer or non-small cell lung cancer did not show a survival benefit of LMWH administration, compared with placebo [40].

Although some of these observations arise from post-hoc analyses, together these data suggest that LMWHs may have a modifying effect on tumor biology, especially in patients with non-metastatic disease. It is unlikely that the effect simply arises due to a reduced frequency of fatal PE because there was no obvious survival benefit during the acute treatment period, and the benefits of LMWH therapy were observed for several months afterwards [36-38]. Thus, a mechanism that is independent of the antithrombotic effects of heparins may be responsible. LMWHs have been shown to modify tumor growth by mechanisms that include inhibition of angiogenesis, tumor growth factors, heparinase and thrombin generation [41, 42]. An antiangiogenic effect is an appealing possibility [43, 44] and is consistent with the observations of the FAMOUS and CLOT studies $[35,36]$ where a survival benefit was evident in patients with limited disease and persisted beyond the treatment period. Heparins may also have direct effects on tumor cell activity, influencing tumor cell invasion and metastasis [44].

\section{Recommendations for Routine Thromboprophylaxis with LMWH}

Surgery in cancer patients is associated with a high risk of VTE, and the administered dose of LMWH should take into account the high-risk situation. There are several LMWHs on the market, and manufacturers generally provide information on the dose appropriate for high-risk patients. Although several studies demonstrate the benefit of prolonged prophylaxis, the optimal duration of postoperative thromboprophylaxis remains unclear.

The ACCP recommend the use of thromboprophylaxis in acutely ill medical patients, including patients with active cancer who are confined to bed with acute illness [8]. These patients are considered to be high-risk, and currently enoxaparin and dalteparin are licensed in Germany for this situation. While some studies have shown a survival benefit for cancer patients who have received short-term LMWH, there is currently no evidence to support their routine use in cancer patients to increase survival.

\section{Conclusion}

Compared with non-cancer patients, patients with cancer have a higher risk of VTE and recurrent VTE, in addition to increased bleeding rates following oral anticoagulant therapy, and some degree of resistance to therapy with UFH. Several LMWHs have demonstrated superior efficacy to UFH or oral anticoagulant therapy in the prevention or treatment of VTE, without increasing the risk of bleeding. These clinical benefits and the well-documented disadvantages of older therapies in cancer patients suggest that LMWH should be increasingly considered for the management of cancer-associated thrombosis.

\section{References}

1 Rickles FR, Edwards RL: Activation of blood coagulation in cancer. Trousseau's syndrome revisited. Blood 1983;62:14-31.

2 Sallah S, Wan JY, Nguyen NP: Venous thrombosis in patients with solid tumors: determination of frequency and characteristics. Thromb Haemost 2002; 87:575-5794.

3 White RH, Zhou H, Romano PS: Incidence of symptomatic thromboembolism after different elective or urgent surgical procedures. Thromb Haemost 2003;90:466-4554.

4 Johnson MJ, Spoule M, Paul J: The prevalence and associated variables of deep venous thrombosis in patients with advanced cancer. Clin Oncol 1999; 11:05-110.

5 Gomes MPV, Deitcher SR: Diagnosis of venous thromboembolic disease in cancer patients. Oncology 2003;17:126-1377.

6 Falanga A, Rickles FR: Pathophysiology of the thrombophilic state in the cancer patient. Semin Thromb Hemost 1999;25:173-182.

7 Goldenberg N, Kahn SR, Solymoss S: Markers of coagulation and angiogenesis in cancer-associated venous thromboembolism. J Clin Oncol 2003;21: 4194-4199.
8 Geerts WH, Pineo GF, Heit JA, Bergqvist D, Lassen MR, Colwell CW, Ray JG: Prevention of venous thromboembolism. The seventh ACCP conference on antithrombotic and thrombolytic therapy. Chest 2004;126:338S-400S.

9 Clagett PG, Reisch JS: Prevention of venous thromboembolism in general surgical patients. Results of a meta-analysis. Ann Surg 1988;208: 227-240.

10 International Multicentre Trial: Prevention of fatal postoperative pulmonary embolism by low doses of heparin. Lancet 1975;ii:45-51.

11 Samama M, Bernard P, Bonnardot JP, CombeTamzali S, Lanson Y, Tissot E: Low molecular weight heparin compared with unfractionated heparin in prevention of postoperative thrombosis. $\mathrm{Br}$ J Surg 1988;75:128-131.

12 Kakkar VV, Cohen AT, Edmonson RA, Phillips MJ, Cooper DJ, Das SK, Maher KT, Sanderson RM, Ward VP, Kakkar S: Low molecular weight versus standard heparin for prevention of venous thromboembolism after major abdominal surgery. Lancet 1993;341:259-265.
13 Bergqvist D, Burmark US, Flordal PA, Frisell J, Hallbook T, Hedberg M, Hom A, Kelty E, Kvitting P, Lindhagen A: Low-molecular weight heparin started before surgery as prophylaxis against deepvein-thrombosis: 2,500 versus 5,000 anti-Xa units in 2,070 patients. Br J Surg 1995;82:496-501.

14 ENOXACAN Study Group: Efficacy and safety of enoxaparin versus unfractionated heparin for prevention of deep vein thrombosis in elective cancer surgery: a double-blind randomised multicentre trial with venographic assessment. Br J Surg 1997; 84:1099-1103.

15 Bergqvist D, Agnelli G, Cohen AT, Eldor A, Nilsson PE, Le Moigne-Amrani A, Dietrich-Neto F; ENOXACAN II Investigators: Duration of prophylaxis against venous thromboembolism with enoxaparin after surgery for cancer. N Engl J Med 2002;346:975-980.

16 Rasmussen MS, Jorgensen PW, Jorgensen LN, Nielsen JD, Horn A, Mohn A-C, Somod L, Olsen B, Harvald T, Pilsgaard B, Neergaard K, Hansen H: Prolonged thrombosis prophylaxis with low molecular weight heparin (dalteparin) following major abdominal surgery for malignancy. Blood 2003;102: 146(abstr). 
17 Heit JA, O'Fallon WM, Petterson TM, Lohse CM, Silverstein MD, Mohr DN, Melton LJ 3rd: Relative impact of risk factors for deep venous thrombosis and pulmonary embolism: a population-based study. Arch Intern Med 2002;162: 1245-1248.

18 Karthaus M, Kretschmar A, Kröning H, Biakhov M, Irwin D, Marschner N, Slabber C, Fountzilas G, Garin A, Abecasis NG, Baronius W, Steger GG, Sudhoff T, Giorgetti C, Reichardt P: Dalteparin for the prevention of catheter-related complications in cancer patients with central venous catheters: final results of a double-blind, placebo-controlled phase III trial. Ann Oncol 2006;17:289-296.

19 Koopman MMW, Prandoni P, Piovella F, Ockelford PA, Brandjes DP, van der Meer J, Gallus AS, Simonneau G, Chesterman CH, Prins MH: Treatment of venous thrombosis with intravenous unfractionated heparin administered in the hospital as compared with subcutaneous low-molecular weight heparin administered at home. N Engl J Med 1996; 334:682-687.

20 Levine MN, Gent M, Hirsh J. Leclerc J, Anderson D, Weitz J, Ginsberg J, Turpie AG, Demers C, Kovacs $\mathrm{M}$ : A comparison of low-molecular weight heparin administered primarily at home with unfractionated heparin administered in the hospital for proximal deep vein thrombosis. N Engl J Med 1996; 334:667-681.

21 The Columbus Investigators: Low molecularweight heparin in the treatment of patients with venous thromboembolism. N Engl J Med 1997;10: 663-669.

22 Weitz JI: Low-molecular-weight heparins. N Engl J Med 1997:337:688-699.

23 Gitter MJ, Jaeger TM, Petterson TM, Gersh BJ, Silverstein MD: Bleeding and thromboembolism during anticoagulant therapy: a population-based study in Rochester, Minnesota. Mayo Clin Proc 1995;70:725-733.

24 Hutten BA, Prins MH, Gent M, Ginsberg J, Tijssen JG, Buller HR: Incidence of recurrent thromboembolic and bleeding complications among patients with venous thromboembolism in relation to both malignancy and achieved international normalized ratio: a retrospective analysis. J Clin Oncol 2000;18 3078-3083.

25 Prandoni P, Lensing AW, Piccioli A, Bernardi E, Simioni P, Girolami B, Marchiori A, Sabbion P, Prins MH, Noventa F, Girolami A: Recurrent venous thromboembolism and bleeding complications during anticoagulant treatment in patients with cancer and venous thrombosis. Blood 2002; 100:3848-3488.
26 Athanasoulis CA, Kaufman JA, Halpern EF, Wallman AC, Geller SC, Fan CM: Inferior vena caval filters: a review of a 26-year single-centre clinical experience. Radiology 2000;21:54-66.

27 Decousus H, Leizorovicz A, Parent F, Page Y, Tardy B, Girard P, Laporte S, Faivre R, Charbonnier B, Barral FG, Huet Y, Simonneau G: A clinical trial of vena caval filters in the prevention of pulmonary embolism in patients with proximal deepvein thrombosis. N Engl J Med 1998;338:409-415.

28 Hansson PO, Sorbo J, Erikson H: Recurrent venous thromboembolism after deep vein thrombosis incidence and risk factors. Arch Intern Med 2000;160: 769-774.

29 Lee AYY, Levine MN, Baker RI, Bowden C, Kakkar AK, Prins M, Rickles FR, Julian JA, Haley S, Kovacs MJ, Gent M: Low-molecular weight heparin versus a coumarin for the prevention of recurrent venous thromboembolism in patients with cancer. N Engl J Med 2003;349:146-153.

30 Hull R, Pineo G, Mah A, Brant RF, for the LITE Investigators: A randomized trial evaluating longterm low-molecular-weight heparin therapy for three months versus intravenous heparin followed by warfarin sodium. Blood 2002;100 (suppl):148a.

31 Buller HR, Agnelli G, Hull RD, Hyers T, Prins M, Raskob GE: Antithrombotic therapy for venous thromboembolic disease. Chest 2004;126:401S$428 \mathrm{~S}$

32 Green D, Hull RD, Brant R, Pineo GF: Lower mortality in cancer patients treated with low molecular-weight versus standard heparin. Lancet 1992; 339:476.

33 Siragusa, Comi B, Piovella F, Hirsch J, Ginsberg JS Low-molecular weight heparins and unfractionated heparin in the treatment of patients with acute venous thromboembolism. Results of a meta-analysis. Am J Med 1996;100:269-277.

34 Hettiarachchi RJK, Smorenberg SM, Ginsberg J, Levine M, Prins MH, Buller HR: Do heparins do more than just treat thrombosis? Thromb Haemost 1999;82:947-952.

35 Kakkar AK, Levine MN, Kadziola Z, Lemoine NR, Low V, Patel HK, Rustin G, Thomas M, Quiqley $\mathrm{M}$, Williamson RC: Low molecular weight heparin, therapy with dalteparin, and survival in advanced cancer: the Fragmin Advanced Malignancy Outcome Study (FAMOUS). J Clin Oncol 2004;22: 1944-1948.
36 Lee AYY, Rickles FR, Julian JA, Gent M, Baker RI, Bowden C, Kakkar AK, Prins M, Levine MN: Randomized comparison of low molecular weight heparin and coumarin derivatives on the survival of patients with cancer and venous thromboembolism. J Clin Oncol 2005;23:2123-2129.

37 Klerk CP, Smorenburg SM, Otten HM, Lensing AW, Prins MH, Piovella F, Prandoni P, Bos MM, Nichel DJ, van Tienhoven G, Buller HR: The effect of low molecular weight heparin on survival in patients with advanced malignancy. J Clin Onco 2005;23:2130-2135.

38 Lebeau B, Chastang C, Brechot JM, Capron F, Dautzenberg B, Delaisements C, Mornet M, Brun J, Hurdebourcq JP, Lemarle E: Subcutaneous heparin treatment increases survival in small cell lung cancer. 'Petites Cellules' Group. Cancer 1994;74: $38-45$.

39 Altinbas M, Coskun HS, Er O, Ozkan M, Eser B, Unal A, Cetin M, Soyuers S: A randomized clinical trial of combination chemotherapy with and without low-molecular-weight heparin in small cell lung cancer. J Thromb Haemost 2004;2:266-1271.

40 Haas S, Kakkar AK, Kemkes-Matthes B, Freund M, Gatzemeier U, Heilmann L, von Tempelhoff GF, Brom J, Weidinger G: Prevention of venous thromboembolism with low-molecular-weight heparin in patients with metastatic breast or lung cancer - results of the TOPIC studies. J Thromb Haemost 2005;3(suppl 1):OR059.

41 Zacharski LR, Ornstein DL, Mamourian AC: Lowmolecular weight heparin and cancer. Semin Thromb Hemost 2000;26(suppl 1):69-77.

42 Mousa S A: Anticoagulants in thrombosis and cancer. The missing link. Semin Thromb Hemost 2002;28:45-52

43 Mousa SA, Mohamed S: Anti-angionetic mechanisms and efficacy of the low molecular weight heparin, tinzaparin: anti-cancer efficacy. Oncol Rep 2004;12:683-688.

44 Da Silva MS, Horton JA, Wijlath JM, Blystone LW, Fish WR, Wijelath E, Strand K, Blystone SD, Sobe M: Heparin modulates integrin-mediated cellular adhesion: specificity of interactions with alpha and beta subunits. Cell Commun Adhes 2003;10:59-67 